\title{
DA ESCOLA COMO OBRA DE ARTE ÀS IMAGENS DE ESCOLAS REMOTAS EM TELAS FRIAS DIGITAIS
}

\section{FROM SCHOOL AS A WORK OF ART TO IMAGES OF REMOTE SCHOOLS ON COLD DIGITAL SCREENS}

\author{
Camilla Borini Vazzoler Gonçalves ${ }^{1}$ \\ Eliana Aparecida de Jesus Reis ${ }^{2}$ \\ Tânia Mara Zanotti Guerra Frizzera Delboni ${ }^{3}$
}

\begin{abstract}
Resumo: Objetiva entrar em relação com os enunciados discursivos veiculados em diferentes sites, blogs e canais no YouTube, problematizando os modos em que somos afetados por uma imagem de escola que precisa deter o saber e por uma imagem de criança concebida/compreendida como um depósito "vazio" que necessita ser preenchida por informações e dados superfaturados de saber. Metodologicamente, embarcamos em um movimento cartográfico para, no encontro com diferentes sites, analisar enunciados que invadem as telas frias digitais em tempos de pandemia e adentraram casas de professores e estudantes. Conversa com Deleuze, Guattari, Foucault e Rolnik para "conspirar" essa escrita, no desejo de continuar apostando na criação/invenção de micropolíticas ativas que abrem poros de respiração em meio à sensação de "eu não consigo respirar".
\end{abstract}

Palavras-chave: Educação; currículo; pandemia.

\begin{abstract}
It aims to enter into relationship with the discursive statements broadcast on different sites, blogs and channels on You Tube, problematizing the ways in which we are affected by an image of a school that needs to retain knowledge and by an image of a child conceived / understood as a deposit "emptiness" that needs to be filled with information and overpriced knowledge. Methodologically, we embarked on a cartographic movement to, in the encounter with different websites, analyze statements that invaded cold digital screens in times of pandemic and entered the homes of teachers and students. Talk to Deleuze, Guattari, Foucault and Rolnik to "conspire" this writing, in the desire to continue betting on the creation/invention of active micropolitics that open pores of breath amid the sensation of "I can't breathe".
\end{abstract}

Keywords: Education; curriculum; pandemic.

\section{Introdução}

A escola como obra de arte se constitui em linhas errantes no plano de uma vida em imanência (DELEUZE; GUATTARI, 2000), onde práticas de si são coletivamente engendradas e inventadas no cotidiano escolar, no sentido de que possibilitam a invenção de uma estética da existência, ao fazer da vida uma obra de arte a partir do cuidado de si e do outro (FOUCAULT, 1995). A potência política do cuidado de si está na criação de outras formas de vida, na necessidade de se criar um mundo de experimentações. Assim, na escola como obra de arte, os corpos-pensamentos vibram, provocam ressonâncias de afetos que escapam a mecanismos de controle, buscando fôlego em experiências que se deslocam das imagens de uma escola cristalizada pelo medo de errar, de ficar para trás, de "perder o ano".

\footnotetext{
${ }^{1}$ Universidade Federal do Espírito Santo, ES, Brasil.

${ }^{2}$ Universidade Federal do Espírito Santo, ES, Brasil.

${ }^{3}$ Universidade Federal do Espírito Santo, ES, Brasil.
} 
Em 2020, ano marcado por escolas de prédios fechados e aulas remotas em virtude da pandemia do novo Coronavírus, encontramos, em enunciados veiculados em diferentes sítios eletrônicos, a naturalização de uma imagem de escola modelar que sai dos manuscritos do século XVIII para invadir as telas digitais do século XXI. A escola remota invade o cotidiano de crianças e de suas famílias que são, repentinamente, desconectadas dos espaçostempos da escola constituída como obra de arte no encontro de corpospensamentos que vibram para liberar sua potência de vida por meio de corredores cheios de vida, ruídos cheios de risos, gritos cheios de afetos.

Navegando por sítios eletrônicos somos surpreendidos por uma cadeia discursiva por meio de enunciados que reforçam a sacralização do saber constituído pela escola ultra-conservadora. Manipulada por uma minoria, as políticas educacionais em curso impõem um padrão normatizado por uma escola que tenta compensar o "tempo perdido" pela falta de aulas devido à pandemia. Como exemplo, podemos citar alguns enunciados veiculados pelo site do Instituto Ayrton Senna durante o ano de 2020. Algumas dessas ações foram realizadas em parceria com a União Nacional dos Dirigentes Municipais de Educação (Undime), numa das inúmeras parcerias público-privada: "O que as redes de educação podem fazer para promover aprendizagem e tempo pedagógico de forma equitativa, mesmo com as escolas fechadas"; "O Instituto Ayrton Senna oferece um guia de gestão de aprendizagem com ações práticas"; "Confira metodologias para reduzir as defasagens de aprendizagem causadas pela pandemia". O site "Todos pela Educação" disponibiliza diversas lives e webnários, tais como: "Aulas suspensas, e agora? Como a família pode apoiar a Educação em tempos de pandemia"; "Como avaliar em tempos de pandemia?".

Ao entrar em relação com os enunciados discursivos veiculados em diferentes sites, blogs e canais no YouTube somos afetados por uma imagem de escola que precisa deter o saber e por uma imagem de criança concebida/compreendida como um depósito "vazio" que precisa ser preenchido por informações e dados superfaturados de saber. São muitas as receitas de ensinar. São muitas as tentativas, por vezes frustradas, que correm contra o tempo chronos com o intuito de fazer algo para que os estudantes não "percam o ano".

Assim, o campo problemático dessa escrita foi se delineando no sentido de colocar o pensamento em movimento: Que saberesfazeres de professores e estudantes invadem as telas frias digitais em tempos de aulas remotas? Que modos de escolas vieram morar em nossas casas? Que afetos são produzidos por uma escola que adentra a casa de crianças, adolescentes, jovens e adultos? De que modo somos capturados pela lógica neoliberal e ultra-conservadora de escola? Que conhecimentos são produzidos por entre as telas frias digitais impostas pelos tempos pandêmicos?

Como aporte metodológico, embarcamos em um movimento cartográfico para, no encontro com diferentes sites, analisar enunciados que invadiram as telas frias digitais em tempos de pandemia e adentraram casas de professores e estudantes. Argumentamos que mesmo diante a receituários, listas de atividades pedagógicas, ações práticas "instantaneamente" elaboradas por especialistas do saber, há possibilidades de produção de afetos e sentidos outros para as aprendências. Como intercessores teóricos, apresentamos Deleuze, Guattari, Foucault e Rolnik para "conspirar" conosco essa escrita.

Com a força da nossa argumentação, desejamos continuar apostando na criação/invenção de micropolíticas ativas que abrem poros de respiração em meio à sensação de "eu não consigo respirar". Considerando os planos intensivos e extensivos de forças que coabitam processos de aprenderensinar, por entre linhas duras, flexíveis e linhas de fuga, queremos desejar a diferença de formas, linhas, cores, lógicas, pensamentos. Refutamos um modelo cristalizado, endurecido na composição de currículos, de escolas, de vida. Por entre formas e forças de natureza macro e micropolíticas, vamos rasurando a anormalidade imposta pelos tempos pandêmicos e criando outros modos de entrar em relação com os processos de aprenderensinar fora da escola. Inauguramos 
tentativas outras de nos constituir como corpo ético, estético e político na criação de micropolíticas ativas para a expansão da vida, da própria existência, para fazer da escola e da vida uma obra de arte.

\section{As telas frias e a força da vida como obra de arte}

Ganhar e perder são lógicas operantes quando a educação serve ao mercado e este serve aos interesses das grandes corporações nacionais e internacionais. Instituições como Instituto Unibanco e Todos pela Educação, por exemplo, aparecem nas notas de rodapé de pareceres institucionais que tornam legítima a escola remota para a educação básica tendo como justificativa o objetivo de não "perder o ano". Alianças público-privadas são naturalizadas, desconsideram o contexto socioeconômico de uma maioria em detrimento de uma minoria dominante e colocam em "modo avião" o direito de todos e todas à educação.

Para Deleuze (2013) nós vivemos à base de cifras. Pouco importa os indivíduos, o que interessa são os números e códigos que possam ser mensurados no lucro das grandes corporações e os índices assinalados nas telas frias do capitalismo financeirizado. A escola remota não chega em todos os lugares, o que acentua as desigualdades e naturaliza as violências. Nesse jogo mirabolante de quem perde e quem ganha o ano letivo, sentimos nossa potência de agir diminuída quando, ao entrarmos em relação às telas sofisticadas do século XXI, encontramos uma overdose de discursos-formas instituídos pela lógica neoliberal de escola-mercado que nos impõe, de modo redundante, a mecanização dos processos de aprenderensinar.

Um ou dois cliques numa tela digital à procura de atividades escolares para crianças é o suficiente para perceber o quanto as mídias ultramodernas estão com suas telas cheias do clássico "bê-á-bá" herdado pela "dita-dura" e suas interfaces mecanizadas de ensinar e aprender. Em meio ao contexto de suspensão de aulas presenciais, somos afetados por forças capitalísticas (ROLNIK, 2018) e, agora, também pandemônicas. Os riscos e ameaças à educação avançam ultra-veloz-mente por entre curtidas de memes e golpes de retroescavadeiras, que abrem valas/sepulturas divulgadas em horário nobre na TV aberta, em contagem progressiva de mortos pela Covid-19.

Enquanto isso, por trás das telas da escola remota, o corpo-docente segue solitário em relação à fibra ótica invisível, sem corpo-abraço, sem cheiro, sem movimentos, sem vida. $\mathrm{Na}$ tentativa de reproduzir a escola do prédio na escola de casa, entre uma desconexão e outra, frente à tela fria do computador/celular, a docência se cala estarrecida diante da imagem de câmeras fechadas e áudios desligados impostos pela inércia do ensino remoto.

A retomada do velho bê-á-bá, nesse contexto de escola remota, dita-dura-mente os modos de ensinar e de aprender. No entanto, o modo conservador de conceber os processos de escolarização de crianças é agora revestido pelos modos sofisticados de domínio do inconsciente colonialcapitalístico (ROLNIK, 2018) que, por sua vez, são regados por doses alucinadas de tecnologias da comunicação e informação. Diante dessa sensação de mal-estar provocada por uma lógica cafetinada (ROLNIK, 2018) de currículos, de escolas, de educação - entre o que aumenta nossa potência de agir e o que produz tristeza e resignação -, somos convocados a engendrar resistências ativas e, em devir-larva, criar poros de respiração por entre a lama tóxica colonial-capitalística que impõe uma lógica perversa que produz morte, sequestra a vida, nos afasta de nossa potência vital.

Entretanto, como uma dobra, a vida como obra de arte carrega a intencionalidade de uma aproximação entre a vida e a Arte. Não no sentido de um fazer artístico enquanto obra exterior a si, mas no sentido de fazer de si uma obra de arte. Isso significa tomar a vida como um exercício ético-estético-político de criação de processos de subjetivação, não assujeitados ou assujeitadores. Nesse sentido, formas de pensar não dogmáticas fazem jogos de força com as liberdades possíveis e inventam outros sentidos, produzem outros modos de vida. 
É nesse sentido que a arte de viver busca opor-se às formas de fascismo, cuja característica está na rejeição e enfraquecimento do indivíduo e que, atualmente, “[...] irá tensionar ao extremo o império da economia" (CENTELHA, 2019, p. 33). O movimento que acompanhamos é uma vontade de opor-se aos pensamentos dogmáticos e a esse fascismo econômico, cujas linhas de vida se dedicam ao entristecimento dos sujeitos que quando tomados por afetos tristes, diminuem a potência de agir.

Acompanhamos o golpe econômico sobre as escolas e a avassaladora aliança públicoprivada na produção de conteúdos em um loop de repetição infinita. As aulas gravadas por grandes corporações, disponibilizadas via YouTube, mascaradamente insistem em produzir práticas discursivas nos quais escolas, currículos e processos de ensinoaprendizagem são sinônimos de um repasse unilateral e frenético de conteúdos. Um jogo puramente econômico, que força professores e estudantes a se colocarem "voluntariamente" frente a uma tela digital para consumir a qualquer custo os conteúdos curriculares; isso tudo mantendo, muitas vezes, seus microfones automaticamente silenciados para garantir o sucesso da (des)conexão da internet que, ao modo banda larga, chega de fato a muitos poucos.

Além disso, é preciso lembrar que as perdas vividas nessa cafetinagem (ROLNIK, 2018) concentram-se em determinados setores da população (CENTELHA, 2019). Desigualdades naturalizadas por dispositivos midiáticos no tratamento oportunista de informações são colocadas em evidência a cada divulgação estatística sobre o acesso a direitos básicos como saúde, educação, tecnologias de informação e comunicação.

Considerando, desse modo, o arrastão econômico que sofre a educação brasileira, precisamos "[...] entrever um mundo povoado não de coisas, mas de forças, não de sujeitos, mas de potências, não de corpos, mas de elos" (COMITÊ INVISÍVEL, 2016, p. 94). E é nesse jogo de forças que, de alguma maneira, abrimos poros para respirar nesse lamaçal capitalístico. Em processos de devir, estudantes atravessam o caos e criam estratégias para suportar a dor de estudar frente a uma tela fria. Como Culp (2020) problematiza, o devir é um processo de desdevir, sendo que este "[...] opera uma desarticulação, um processo que 'desfaz a estabilidade das identidades, do conhecimento, da localização e do ser"” (CULP, 2020, p. 70).

Frente às telas frias digitais, que por meio da fibra óptica repetem o conteúdo-conteúdoconteúdo, os estudantes criam um devir-outro que se opõe a esses planos de austeridade. Recusam, ao seu modo, estratégias de reprodução das listas de competências e habilidades prescritos pela lógica neotecnicista de ensino e aprendizagem resultante da aliança entre o ultraconservadorismo pedagógico e os interesses neoliberais. Os estudantes manipulam a velocidade de reprodução dos vídeos (aceleram o tempo de transmissão dos vídeos), trocam mensagens uns com os outros, sabotando espaços da tela para os comentários da/na videoaula. Produzem ruídos à sua maneira. Riem e debocham dessa máquina que tenta a qualquer custo os enquadrar em uma fórmula conteudista e escolhem fazer da vida uma obra de arte. Rasuram o silêncio condicionado que tenta calar os encontros e intensificam os ruídos que dão vida e sentido aos processos de aprenderensinar.

Assim, "[...] a arte luta com o Caos, mas para torná-lo sensível" (DELEUZE; GUATTARI, 2000, p. 263). De alguma maneira, a arte mergulha no Caos para atualizar alguma virtualidade e produzir agenciamentos, nos quais os corpospensamentos se recusam a sentar frente às telas frias do velho bê-á-bá e consumir, mecanicamente, os conteúdos. Resistem aos mecanismos cifrados da máquina capitalística que busca capturá-los, criam outros mundos, agenciam outras forças e dão indícios para que a vida se produza como obra de arte mesmo diante das codificações cifradas de currículos mecanizados nas telas digitais.

As aulas remotas tomaram a vida de todos os estudantes em 2020. As instituições privadas produziram uma lista imensa de vídeos, cujos conteúdos são ministrados quase como um programa de TV. Redes públicas de ensino compraram plataformas digitais com materiais pré- 
programados de acordo, dita-dura-mente, com a Base Nacional Comum Curricular (BNCC). Seja por meio das inúmeras propagandas de sites educativos que invadem telas de celulares e computadores ou por meio de uma abordagem sedutora e pretensiosa, vendem, ilusoriamente, com o velho be-a-bá pedagógico, a lógica de que escola e currículo são sinônimos de conteúdoconteúdo-conteúdo, oferecendo às famílias, crianças e adolescentes o acesso às aulas via YouTube e outras plataformas que cumprem com eficiência a reprodução mecanizada do conhecimento na tentativa de anular os processos de subjetivação da docência, os movimentos inventivos de aprendências ativas que fazem gaguejar os processos de aprenderensinar.

Crianças e adolescentes receberam o conteúdo curricular por meio das telas e, independente da condição de moradia, saneamento básico, alimentação, emprego e renda, acesso a equipamentos eletrônicos e à internet, a educação estava garantida, bastava acessar a plataforma a qualquer momento e consumir a overdose de conteúdos pré-estabelecidos pelas formas neoliberais para saciar a sede de lucro acima do lucro de tudo e de todos. Vende-se a ideia de que a escola se limita ao repasse de conteúdos e que a docência confere apenas o papel de mero transmissor e reprodutor de aulas-aulas-aulas. A lógica de mercado/empresa chega por todos os lados e de toda forma. Sufoca. Faz agonizar a docência. Compra-se "gozosamente" esse discurso produzido pela máquina neoliberal midiática.

Mas, a educação "[...] é sempre um exercício e uma demonstração em relação à igualdade de singularidades do comum” (NEGRI; HARDT, 2014, p. 103). A educação, assim, acontece no contato, no olhar, na troca, no ouvir e falar, está na relação entre os sujeitos, nunca em uma relação solitária frente a uma tela digital. As trocas de mensagens entre os estudantes evidenciam essa necessidade de estar com. Eles compartilham as angústias do ensino remoto e também algumas conquistas, tentando fugir da solidão que os sufoca para não sucumbirem.

Intencionamos, desse modo, buscar os atravessamentos e rupturas criadas pelos estudantes ao assistirem as videoaulas oferecidas pelos sistemas de ensino público. Vasculhamos os comentários das vídeo aulas de matemática para o $9^{\circ}$ ano produzido pelo "Centro de Mídias de Educação do Amazonas", cujo material foi adquirido pela Secretaria de Educação do Estado do Espírito Santo e disponibilizado aos estudantes regularmente matriculados na rede estadual de ensino. Os comentários sinalizam a tensão produzida quando os estudantes entram em relação a este currículo mecanizado. Eles criam estratégias de resistência que nos dão indícios que a escola não se circunscreve a um currículo conteudista ultra-conversador, mas de que ela é o lugar do encontro, do afeto, do barulho, da amizade, das trocas; é o lugar de fazer da vida uma obra de arte... E a vida como obra de arte não se rende à cafetinagem.

$\mathrm{Na}$ relação com as telas frias e com a saudade da escola, do recreio, da coordenação, dos colegas os estudantes apontam os possíveis para uma vida como obra de arte. Atravessados por esse mundo pandêmico e uma escola solitária, encontram nos comentários das videoaulas meios de relembrar os afetos engendrados nos encontros da/na/com a escola e produzem redes de afetos, mesmo que por um instante, frente à solidão que invade o ensino remoto.

Os comentários enunciam a saudade da escola, das idas ao banheiro; das trocas de materiais escolares; dos momentos com a coordenação; das conversas entre os estudantes. São enunciados, dentre tantos outros, que dão indícios que a escola não se resume a uma questão de conteúdo ou de currículos mecanizados, em que os estudantes e professores assumem um falso papel de transmissor e receptor de um pré-determinado conhecimento. Mas é a aposta de que a escola é o lugar do encontro.

A saudade da escola e dos cadernos. "Alguém viu meu caderno?" pergunta uma aluna em uma das aulas. "Debaixo da mesa", responde outro aluno. O diálogo rememora o momento da escola, de cadernos perdidos e achados. Mas, acima de tudo, rememora o encontro, as redes de amizade. A pergunta da estudante pode parecer um pouco estranha, considerando o contexto da aula remota, mas concordamos com Culp (2020, p. 70), que “[...] é somente quando localizamos 
algo verdadeiramente intolerável fora de nós que somos capazes de 'saltar para fora da vergonha' e "transformar [nossas] miseráveis empreitadas em guerras de resistência e libertação"”.

Talvez o caderno seja um dos elementos que mais nos fazem lembrar da escola. É nele que estudantes e professores registram - ou não - suas composições curriculares. Mas, é também nesse artefato que as canetas coloridas imprimem as linhas de subjetividades, tracejam suas marcas pela/na/da escola. "Vou copiar a matéria do seu caderno...". São também dos cadernos que pequenos pedaços de papel são arrancados para que recados secretos sejam transmitidos numa rede de comversações que segue clandestina por entre corredores e silêncios que gritam criações/invenções.

Por entre fibras ópticas invisíveis, cliques insurgentes resistem à passividade e à servidão remota. Os alunos engendram resistências ativas, enunciam saudades da escola e, em devir-larva, criam poros de respiração diante da lama capitalística que insiste em produzir que o currículo cabe em videoaulas.

\section{Em movimento sem fim...}

Diante das telas frias, velozes e furiosas da escola remota o corpo-docente segue ofegante por entre as forças intensivas e extensivas da fibra ótica que pulsa invisível, sem corpo, sem cheiro, sem vida. Na tentativa de reproduzir a escola do prédio na escola de casa, entre uma des-conexão e outra, a docência corre o risco de ser reduzida àquela que se cala estarrecida diante das telas de áudios desligados e câmeras fechadas na clausura imposta pelo ensino remoto.

No plano da vida somos afetados por paixões alegres e por paixões tristes. Em contato com afecções inadequadas, o corpo produz tristeza, resignação, medo. Isso diminui nossa potência de agir, lançando-nos à passividade, à servidão. No entanto, quando há afecções adequadas, são produzidos afetos ativos que, ao aumentar no corpo a potência de agir, nos possibilitam criar outros modos de existir. Saímos do plano da vontade para, na composição coletiva, criar/inventar uma ruptura com as servidões subjetivas que tentam nos capturar.

A retomada do velho be-a-bá, nesse contexto de escola remota, dita-dura-mente os modos de ensinar e de aprender. No entanto, o modo ultra-conservador de conceber o currículo, a escola, os processos de ensinar e aprender, é agora revestido pelos modos sofisticados de domínio do inconsciente colonial-capitalístico (ROLNIK, 2018) que, por sua vez, são regados por doses alucinadas de tecnologias da comunicação e informação. Diante dessa sensação de mal-estar provocada diante da imagem de escola cafetinada, entre o que aumenta nossa potência de agir e o que produz tristeza e resignação, entre esses dois movimentos paradoxais, somos convocados a engendrar resistências ativas e, em devir-larva, abrir poros de respiração por entre a lama tóxica colonial-capitalística que impõe a morte sobre a vida, para manejar outros possíveis.

Desejamos continuar apostando numa escola onde a criação/invenção que reverbera nos planos intensivos das forças e dos afetos constituem-se coengendradas por entre linhas duras, flexíveis e linhas de fuga. Queremos desejar a diferença de formas, linhas, cores, lógicas, pensamentos. Refutamos um modelo cristalizado, endurecido na composição da escola, da vida. Por entre formas e forças de natureza macro e micropolíticas estudantes e professores seguem rasurando a anormalidade imposta pelos tempos pandêmicos compondo outros modos de entrar em relação com os processos de aprenderensinar da escola remota, inaugurando tentativas outras de se constituir como corpo ético, estético e político na criação de micropolíticas ativas para a expansão da vida, da própria existência como uma obra de arte.

\section{Referências}

CENTELHA. Ruptura. São Paulo: n-1 edições, 2019. 
COMITÊ INVISÍVEL. Aos nossos amigos. São Paulo: n-1 edições, 2016.

CULP, Andrew. Dark Deleuze pela morte deste mundo. São Paulo: Glac edições, 2020.

DELEUZE, Gilles. Conversações. Trad. Peter Pál Pelbart. 3. ed. São Paulo: Ed. 34, 2013.

DELEUZE, Gilles; GUATTARI, Felix. O que é a filosofia? Rio de Janeiro: Editora 34, 2000.

FOUCAULT, Michel. Sobre a Genealogia da Ética: uma revisão do trabalho. In: DREYFUS, Hubert; RABINOW, Paul. Michel Foucault: uma trajetória filosófica. Rio de Janeiro: Forense Universitária, 1995. p. 253-278.

NEGRI, Antonio; HARDT, Michael. Declaração: Isto não é um manifesto. São Paulo: n-1 edições, 2014.

ROLNIK, Suely. Esferas da Insurreição: notas para uma vida não cafetinada. São Paulo: N-1, 2018.

\section{Sobre as autoras}

Camilla Borini Vazzoler Gonçalves é graduada em Pedagogia pela Universidade Vila Velha, tem Mestrado em Educação (Universidade Federal do Espírito Santo) e atualmente é doutoranda em Educação (Universidade Federal do Espírito Santo). É bolsista da Capes. Desenvolve ações de pesquisa e extensão nas áreas de currículos, infâncias e linguagens na perspectiva da Filosofia da Diferença.

E-mail: camillavazzoler@gmail.com.

Eliana Aparecida de Jesus Reis é graduada em Letras-Português (Faculdade Castelo Branco) e Pedagogia (Universidade de Uberaba), tem Mestrado em Educação (Universidade Federal do Espírito Santo). É professora em função de docência nos Anos Iniciais do Ensino Fundamental e professora em função de assessoramento pedagógico (Pedagoga) do Ensino Fundamental da rede municipal de ensino de Serra/ES. Desenvolve ações de pesquisa e extensão nas áreas de currículos e formação de professores na perspectiva da Filosofia da Diferença.

E-mail: elianareis.edu@gmail.com.

Tânia Mara Zanotti Guerra Frizzera Delboni é graduada em Letras-Inglês (Universidade Federal do Espírito Santo) e Pedagogia (Universidade de Uberaba), tem Mestrado e Doutorado em Educação (Universidade Federal do Espírito Santo). Atualmente faz estágio pós-doutoral na Universidade do Estado do Rio de Janeiro. É professora adjunta da Universidade Federal do Espírito Santo. Desenvolve ações de ensino, pesquisa e extensão nas áreas de currículo e formação de professores na perspectiva da Filosofia da Diferença.

E-mail: tania.delboni@ufes.br. 